\title{
RORTY Y LOS PROBLEMAS DE UNA ÉTICA PRAGMÁTICA
}

\section{Un ensayo de interpretación analógica}

\author{
Rafael Gómez Pardo \\ Universidad Santo Tomás
}

\section{Resumen}

Este ensayo expone las ideas fundamentales de la ética pragmática de Rorty, partiendo de su crítica de la verdad como representación y la propuesta de la solidaridad en un sentido moral. El autor intenta sentar las bases de una crítica a la ética pragmática y establece la necesidad de volver a plantear el tema de la persona -desde un cristianismo más "actualizado"- y se formula el problema de la esencia de lo pragmático al interior de una metafísica que, fundándose un referente simbólico o analógico, supere el dogmatismo y logre inspirar sentimientos como la solidaridad.

\section{Palabras clave:}

Ética pragmática, persona, analogía, solidaridad, referente.

\begin{abstract}
This essay presents the main ideas of the Rorty's pragmatic Ethics, starting from his criticism on the truth as representation and the proposal of solidarity in a moral sense. The author tries to settle the basis for a criticism to the pragmatic Ethics and establishes the need to pose the topic of the person from a Christianity more "actualized" and is also mentioned the problem of the essence of the pragmatic within the inner of a metaphysics that, if founded a symbolic or analogic reference, it would overcomes the dogmatism and would manage to inpire feelings like solidarity.
\end{abstract}




\section{Key words}

Pragmatic Ethics, Person, Analogy, Solidarity, Reference.

Rorty no propone una ética en tanto que ciencia de lo práctico, esto es, como un sistema racional del cual podamos inferir normativamente el significado y el alcance de nuestras acciones. En tal sentido, no encontramos una ética en Rorty. Pero gran parte de su filosofía es precisamente una reflexión sobre la problemática ética y sobre aquellos presupuestos implicados en "lo ético”, no como una teoría, sino como una pragmática. En este ensayo me propongo establecer cuáles son esos presupuestos, dilucidar sus implicaciones, y formular alguna preguntas o críticas generales. Para ello voy a comenzar desarrollando de manera muy sintética la crítica de Rorty a la teoría del conocimiento como "intento de representar la realidad”, con lo cual pasaré a considerar la ética como una "práctica de los sentimientos", y por último, ampliando lo anterior, a desarrollar brevemente el tema de la relación entre el pragmatismo de Rorty y algunos de los problemas más relevantes que, desde un marco de referencia “más amplio” o diferente (analógico), se pueden dilucidar y desarrollar dentro de una investigación.

\section{Crítica al conocimiento como representación}

Desde Aristóteles, la tradición filosofica ha pensado el conocimiento como una representación de lo real. De ahí que la verdad se ha entendido como la adecuación o conformi- dad de la realidad con el juicio. La verdad es algo que se predica de un juicio cuando lo que éste afirma coincide con el ser de la cosa. La verdad es ontológica. Se supone con ello que la realidad está ya dada, y que en sí misma no ofrece ningún problema. El problema está en nuestro intento de conocerla, de corresponder en el acto de conocerla con "su ser”. Esta concepción de la verdad como adecuación ha sido muy fecunda, no sólo en la tradición filosófica antigua y moderna, sino incluso en la ciencia empirista, o en toda concepción del conocimiento en la que encontremos sedimentos de realismo bajo el prurito de objetividad o precisión. La ciencia ha reemplazado esta pretensión de la filosofía de conocer las cosas en su esencia, por el conocimiento de las leyes que gobiernan los fenómenos. Pero al igual que en el realismo, se supone que el fenómeno está ya dado, con lo cual no hay problema. El problema sigue siendo el mismo: la adecuación del juicio al fenómeno. Así, la ciencia sigue pretendiendo que la verdad se encuentra en la representación, en la realidad de algo externo a nosotros mismos. "Saber es representar con precisión lo que hay afuera de la mente” ${ }^{\text {. La }}$ idea de la necesidad de una teoría del conocimiento basada en la comprensión de los procesos mentales es producto del siglo XVII, y determina gran parte de la investigación filosófica moderna, más reciente entendida como investigación acerca de los fundamentos del conocimiento, o como la búsqueda

1 Richard Rorty, La filosofía y el espejo de la naturaleza, trad. de Jesús Fernández Zulaica (Madrid: Cátedra,1979), p. 13. 
de un conocimiento sobre el conocimiento, y luego, como la elaboración de un lenguaje preciso, debidamente formalizado ${ }^{2}$. Todo ello está basado, según Rorty, en la "imagen de la mente como un gran espejo, que contiene representaciones diversas (algunas exactas, y otras no) y se puede estudiar con métodos (...). Sin la idea de la mente como espejo, no se habría abierto paso la noción del conocimiento como representación”’3.

Sin embargo, encontramos en la tradición filosófica otro tipo de filósofos que, antes de Rorty, hicieron una crítica al conocimiento como representación de objetos o de realidades universales o esencias inmutables. Quizás el más destacado y mencionado de los que emprenden esta tarea de demoler la representación y el carácter de realidad de un mundo externo (que comienza siendo un mundo por conocer, y termina en un mundo "para obedecer"), es Nietzsche. "No hay hechos, sólo interpretaciones”, dice. Con ello se intenta desplazar la ontología a la hermenéutica, esto es, desplazar la creencia en una realidad objetiva ya dada, que entrega su verdad en el proceso del conocimiento, al ejercicio de interpretación, pues esa supuesta "realidad” es sólo una interpretación más entre otras muchas posibles. No representa otra cosa fuera de sí misma, no nos remite a un sentido originario que se restituiría por fin a nuestra conciencia para aquietar su incertidumbre. Es en sí misma un ejercicio de invención nunca terminado, una creación desde la "voluntad de poder" como expresión de afirmación de la voluntad de vida, autosuficiente; contiene su propia verdad y su propia necesidad. No se inclina ante ningún ídolo porque no traiciona su propia contingencia, o, en términos de Nietzsche, el sentido de la tierra.
Siguiendo estos lineamientos, la verdad para Foucault no es un asunto que aguarda a ser descubierto, definido desde siempre en un ámbito ajeno a la producción del discurso, y que luego, por obra de un pensamiento atento, disciplinado, ascético, puede ser develado y representado, sino que es una producción del discurso mismo. En otras palabras: la verdad no está referida a unos objetos o a un absoluto que existe por sí mismo desde siempre y que necesitamos representar. Se trata de jugar el juego de interpretar otra vez lo ya interpretado como realidad, y producir verdades y falsedades que nos permitan, no encontrarnos, sino desencontrarnos, transformarnos constantemente a nosotros mismos. Así, el conocimiento y la verdad se convierten en un trabajo "estético" de creación incesante, infinita, y no de representación.

Con el pragmatismo de Rorty, esta crítica a la representación se redefine, llegando a consecuencias pragmáticas un tanto diferentes. Rorty denomina a estos filósofos que lo anteceden en su voluntad de demoler la creencia en la representación, filósofos edificantes, no sistemáticos, o antirrepresentacionistas. Por el contrario, la filosofía sistemática es propia de aquellos filósofos que buscan el fundamento del conocimiento en una facultad o en la mente entendida como un espejo, y que, con frecuencia, se inspiran en el progreso de la epistemología o de una ciencia.

Rorty reconoce que esa idea de la mente como un espejo de la naturaleza se puede considerar como un progreso en la medida en que ha hecho posible la secularización en las sociedades modernas. Gracias a ella, la ciencia tiende a remplazar a la religión respecto a cómo nos representamos la naturale-

2 En particular, los intentos de formalización de teorías lógicas y matemáticas, como la lógica de primer orden y la teoría de los números, campos donde surgieron los resultados más importantes de Gödel. Véase: Francisco Rodríguez Consuegra, ed., Kurt Gödel, ensayos inéditos (Barcelona: Mondadori, 1994) 23.

3 Rorty, La filosofía y el espejo ..., p. 20. 
za. En la ilustración, el filósofo pretende proteger a los hombres ante las ideas de la superstición, pero creando nuevos "territorios de objetividad” que serán colonizados por la ciencia. La pregunta acerca del universo, acerca del hombre, es respondida ahora por las ciencias. En el ámbito de la psicología, la realidad se da en el conocimiento científico de la naturaleza humana; en el de la ética, la realidad como ideal es la idea formal de bien a través de un imperativo categórico universal; y así, en todos los ámbitos, se nos sigue remitiendo a algo universal, objetivo ya no tanto de carácter religioso sino secular, científico. Esta supuesta objetividad científica es un remante que ha quedado de la religión y la metafísica, al cual nos debemos adecuar, y así realizar nuestra esencia moderna como seres que conocen o que buscan la verdad (quizás ya no la verdad absoluta, pero al fin al cabo, la verdad científica respecto a algo). Frente a esta nueva forma de autoridad secular y anónima, el objetivo de Rorty, como él mismo dice, es ayudarnos a liberarnos de actitudes y vocabularios caducos, “acabando con la confianza que el lector pueda tener en la mente en cuanto algo sobre lo que se ha de tener una visión filosófica, y en el conocimiento, en cuanto algo que debe ser objeto de una teoría y que tiene fundamentos, y en la filosofía tal y como se viene entendiendo desde Kant”4.

Rorty anota como un progreso indudable para la investigación filosófica el abandono de la representación como criterio para validar el conocimiento. Sin embargo, él no intenta proponer un criterio distinto, porque no se trata de que él conozca mejor que sus antecesores la "cosa misma”, sea naturaleza humana, mundo físico, verdad o esencia, o in- cluso el conocimiento. Ello implicaría que él sigue atrapado en la necesidad imaginaria de creer que hay esencias como realidades objetivas, y de suponer que la filosofía debe descubrir y mostrar su verdad, o corregir aquellas teorías que no han podido dar cuenta de ellas. Rorty elude completamente ese tipo de indagación. No es que la representación sea falsa, ni que necesite ser corregida, o reemplazada, pues no se trata de indagar la “esencia” de la representación, sino que es más útil, ventajoso y esperanzador abandonar ese criterio anticuado. Hay que reemplazar el conocimiento por la esperanza, dice, o en otras palabras por “aquello que más nos conviene creer" 5 . La pretensión de conocimiento en tanto que representación de algo nos ha de llevar siempre a algún nuevo tipo de objetividad, a algún absoluto, científico o filosófico, y estos, a la intolerancia, a la negación de la libertad. La ciencia moderna está construida sobre los sedimentos de la metafísica.

La crítica a la teoría de la representación en Rorty se presenta desde dos temáticas relacionadas entre sí: en primer lugar, el tema de la filosofía como el espejo de la naturaleza, $\mathrm{y}$ en segundo lugar, el tema de la verdad como justificación de las creencias. La primera de estas se encuentra sintetizada en el capítulo 8, titulado "Filosofía sin espejos", del libro La filosofía y el espejo de la naturaleza. Allí desarrolla lo fundamental de su posición respecto a una crítica al conocimiento científico y a la pretensión del conocimiento en general. Dice: "En toda cultura suficientemente reflexiva hay quienes seleccionan un área, un conjunto de prácticas, y la consideran como el paradigma de la activi-

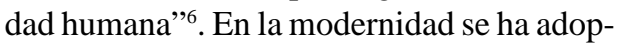

\footnotetext{
Rorty, La filosofía y el espejo ..., p. 16.

Rorty, La filosofía y el espejo ..., p.19.

Rorty, La filosofía y el espejo..., p. 331.
} 
tado el paradigma del conocimiento científico, y del conocimiento, esto es, de la epistemología, como el modelo de validez más riguroso. La imagen que representa el objeto y que se refleja en el espejo es dada hoy por la ciencia. Allí es donde actualmente ocurre la adecuación. El filósofo tendría que remodelar todas las actividades de la cultura y de su conocimiento inspirándose en el modelo del último logro cognitivo. "Ahora que tal o cual línea de investigación ha conseguido un éxito tan sorprendente, vamos a rehacer toda la investigación y toda la cultura inspirándonos en su modelo, haciendo así posible que se impongan la objetividad y la racionalidad en áreas anteriormente oscurecidas por la convención, la superstición y la falta de una adecuada comprensión epistemológica de la capacidad del hombre para representar con exactitud a la naturaleza”7. En efecto, este ideal sistemático proviene de aquellas filosofías que intentan hacer extrapolaciones de los logros de la ciencia en todas las áreas del saber. Hay en estos proyectos un ideal de conmensurabilidad universal que sigue siendo heredero de la metafísica como un intento por descansar por fin en lo absoluto, en el conocimiento definitivo de la verdad.

Este ideal de conmensurabilidad proviene de la idea de que la mente refleja, es decir, de que es un espejo de la naturaleza totalmente limpio, una vez corregidos todos los errores. Pero si ello es así, esto supone la idea utópica de un espejo que no podría distinguirse de lo que se ha reflejado, y que, por lo tanto,

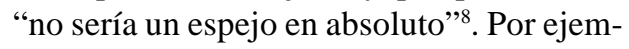
plo: no nos podríamos distinguir de las descripciones que hace una ciencia o de las que hace una religión, pues cualquiera de ellas, al ser reflejadas, nos muestran lo que somos. En otras palabras: "La idea de un ser humano cuya mente es ese espejo limpio, y que sabe esto, es la imagen, como dice Sartre, de Dios, porque esa imagen y lo que refleja, al ser un perfecto reflejo, no serían sino una sola cosa. Este ser no se enfrentaría con algo extraño que le imponga la necesidad de elegir una actitud hacia él o una descripción del mismo. No tendría ninguna necesidad ni capacidad para elegir acciones o descripciones. Puede ser llamado Dios, si pensamos en las ventajas de esta situación, o una simple máquina, si pensamos en sus desventajas. Desde este punto de vista, “el buscar la conmensuración en vez de limitarse a continuar la conversación es intentar escapar de la condición de hombre", asumir responsabilidad frente a lo contingente. Es el deseo ancestral de convertirse en una cosa, de no tener qué elegir, qué creer, qué considerar más verdadero. Es el deseo imposible de negar la contingencia mediante la imagen de algo verdadero y absoluto, referente objetivo que no me plantea más problemas con mi libertad, y frente al cual me alieno completamente, intentando escapar de la condición humana e incierta. Si hay una verdad, yo me transparento con ella, y no tengo ya problemas. Soy su representación. En términos de Sartre, me he convertido en un en sí.

En tal sentido, Rorty relativiza el valor y el alcance de las pretendidas verdades científicas y de la ciencia misma. La ciencia no es sino una descripción más entre muchas descripciones posibles, a pesar de la importancia que muchos de los filósofos y científicos le otorgan en tanto que conocimiento verdadero. Ella ha heredado sedimentos de meta-

Rorty, La filosofía y el espejo..., p. 332.

Rorty, La filosofía y el espejo..., pp. 331-332.

Rorty, La filosofía y el espejo..., p. 340. 
física, en la medida en que aún necesita "representarse" el mundo, crear un nuevo criterio de "objetividad". Sin embargo, según Rorty, ya no necesitamos de esas bases: podemos desmontarlas. Necesitamos concebir la ciencia fundamentalmente como una práctica de creencias que tienen un relativo éxito y cuyas justificaciones están en constante progreso. Lo que hay que preguntarse respecto a la ciencia no es acerca de la verdad de sus pretendidos conocimientos, sino acerca de su utilidad ${ }^{10}$. Con ello, Rorty intenta abandonar la epistemología y pasar a un criterio pragmático para entender la ciencia y su progreso. Mientras sigamos dependiendo de la epistemología, tendremos que retomar el tema de la verdad como representación de algo que existe fuera de la mente. Y ello supone seguir anclados en un lenguaje caduco que, en la perspectiva de Rorty, limita el ejercicio de la libertad.

Rorty elabora un diagnóstico acerca de la herencia nefasta de la epistemología para la filosofía. Consiste en pretender, por parte del filósofo, extraer legitimidad a partir de la validez del conocimiento científico. Ello supone que la filosofía está, como la ciencia, necesitada de representarse el mundo con toda precisión (desde una filosofía como ciencia estricta hasta la precisión de los conceptos en la filosofía analítica, por ejemplo), y que la ciencia le da su verdad desde la idea de una filosofía como sistema. El valor de la ciencia no está en su verdad; estriba más bien en ser un instrumento mejor que otros, no para explicar algo referido a la realidad, sino para llevar a cabo algo. Decir que "la natu- raleza intrínseca de la realidad consiste en átomos y vacío es para el pragmatista una manera de decir que nuestras explicaciones científicas más exitosas interpretan el cambio macroestructural como un resultado del cambio microestructural" ${ }^{11}$. Estas afirmaciones no se refieren a la naturaleza de la materia o a lo que realmente ocurre respecto a un objeto de conocimiento, sino son recomendaciones prácticas acerca de interpretaciones. Lo que está en juego es la pregunta acerca de qué queremos obtener respecto a qué creencia. Quizás la sociedad deba abandonar el criterio de la objetividad, propio de la ciencia, para pasar al criterio de la solidaridad. Abandonar el paradigma del conocimiento para que sea remplazado por la esperanza.

Reemplazar el conocimiento por la esperanza significa "dejar a un lado la idea kantiana de que hay algo denominado la naturaleza del conocimiento humano o la situación cognoscitiva humana o la extensión y los límites del conocimiento humano que los filósofos estudian y describen" ${ }^{\prime 2}$. Lo que estos filósofos describen no son sino sus necesidades de creer en esas ideas. No hay un modo en que el mundo es, y no hay un modo en que pueda ser fielmente representado. En otras palabras: no hay algo así como un cartesiano orden natural de la razones que se debe seguir para justificar las creencias. No hay ninguna actividad llamada conocimiento que tenga una naturaleza a describir y para la cual los científicos naturales estén especialmente dotados. "No nos conocemos mejor a nosotros mismos conociendo un con-

\footnotetext{
10 Dice Rorty: "Nuestros críticos no creen que la distinción útil inútil pueda reemplazar la vieja distinción apariencia realidad”. Richard Rorty, Verdad y progreso, Traducción de Ángel Manuel Faerna García Bermejo (Barcelona: Paidós, 2000) p. 12.

11 Richard Rorty, ¿Esperanza o conocimiento? Una introducción al pragmatismo, traducción de Eduardo Rabosi (Buenos Aires: Fondo de Cultura Económica, 1994), p. 96.

12 Rorty, ¿Esperanza o conocimiento?..., pp. 27-28.
} 
junto de hechos objetivos”13. Hay que abandonar la idea del filósofo, e incluso del científico, "como alguien que conoce algo sobre el conocer que ningún otro conoce tan bien”14. "Existe, sencillamente, el proceso de justificar las creencias ante una audiencia. Y ninguna audiencia está más próxima a la naturaleza ni es mejor representante que cualquier otra" ${ }^{15}$.

Siguiendo a Gadamer, Rorty afirma: "Las ciencias naturales, por sí solas, no llegan a convencernos de que sabemos lo que somos y lo que podemos saber (...) aun cuando sepamos todas las descripciones objetivamente verdaderas de nosotros mismos, quizás sigamos sin saber qué hacer con nosotros”16. Para Gadamer -comentado por Rorty- la hermenéutica no es un método para encontrar la verdad que encaje en la imagen clásica del hombre como ser que conoce. Más bien, lo que hace Gadamer es preguntar “qué conclusiones se pueden deducir del hecho de que tenemos que practicar la hermenéutica”17, o, en otras palabras, cuáles son las más útiles e interesantes consecuencias que podemos sacar del hecho de que no hay una objetividad absoluta ni una verdad objetiva, $\mathrm{y}$ de que, en esa condiciones, tenemos que interpretar. Tenemos que dejar de lado la pregunta acerca del método correcto para interpretar o para conocer, propio de una filosofía cuyo centro es la epistemología y no la hermenéutica, y pasar a una filosofía que no tome en serio ninguna representación, que la interprete como la expresión de una creencia más entre muchas posibles.

Pero volviendo al planteamiento de Sartre comentado por Rorty, la creencia en alguna objetividad en el plano ético nos liberaría de la responsabilidad, y la ética sería sencillamente un catecismo prescriptivo para adecuarnos a la representación de una ética al interior de una teoría filosófica, o, en otras palabras, para adecuarnos a la voluntad, o mejor, a la creencia de “otro” (un filósofo), considerada como verdadera, desde un imperativo categórico o desde cualquier esencia universal. Para Rorty, sólo en la contingencia, en la aceptación de que todos los discursos, sean o no científicos, no pueden representar la verdad, ya que ésta no es algo en sí sino una justificación de ciertas creencias, puede haber libertad, tolerancia y esperanza, y la filosofía, en lugar de ser un sistema que pretende fundar desde el conocimiento de la esencia del conocimiento o lo que sea (la esencia de Occidente como la historia acerca del olvido del ser, por ejemplo), se convierte en una conversación. La ciencia no nos ofrece sino una descripción del mundo en tanto que “objetividades", que deja por fuera otra serie de problemas mucho más interesantes y útiles, como por ejemplo: ¿en qué debemos creer en una sociedad secular?, ¿cómo reemplazar el criterio de objetividad por el criterio de solidaridad? Si las ciencias humanas, por ejemplo, se representan, mediante sus teorías, lo que somos como esencia o como una naturaleza humana, y lo hacen de manera “objetiva”, “exacta”, entonces serían como las religiones o algunas filosofías, en las cuales se nos ofrece la explicación verdadera acerca de nuestro ser. No habría necesidad de elegir, pues tales teorías habrían conseguido llegar a resolver todas las preguntas. Nosotros tendríamos que adecuarnos a la manera como ellas nos representan. Es aquí donde la misma comunidad científica haría las veces de una nueva

\footnotetext{
Rorty, La filosofía y el espejo..., p. 337.

Rorty, La filosofía y el espejo..., pp. 353-354.

Rorty, ¿Esperanza o conocimiento?..., p. 32.

Rorty, La filosofía y el espejo..., p. 328.

Rorty, La filosofía y el espejo..., p. 234.
} 
casta sacerdotal, empeñada en defender sus verdades $^{18}$, sus mejores representaciones de la objetividad fundante, mediante nuevas estrategias de adoctrinamiento y difusión.

\section{La verdad como justificación de las creencias}

La crítica al conocimiento como representación desemboca en el tema de las creencias, y de la verdad como justificación de éstas. El tema es desarrollado en casi todas las obras de Rorty, pero especialmente en Objetividad, relativismo y verdad, y en ¿Esperanza o conocimiento? "Las creencias son reglas para la acción más que intentos de representar la realidad" ${ }^{19}$. Toda la ciencia se puede leer ahora como el lenguaje de algunas creencias y sus múltiples mutaciones. No tiene sentido preguntarse acerca de la verdad de su lenguaje, sino de la siguiente manera: ¿es capaz de justificar plenamente sus creencias? En efecto, en la imposibilidad de conocer objetos y de dar cuenta de ellos, queda la posibilidad de “justificar creencias”. Pero, ¿qué es una creencia? Rorty nos da la siguiente definición: "Concibamos a la mente humana como una trama de creencias y deseos -una trama que continuamente se vuelve a tejer a sí misma para adaptarse a nuevas actitudes oracionales. No nos preguntemos de dónde proceden las nuevas creencias y deseos. Olvidemos, por el momento, el mundo exterior (...) supongamos simplemente que cada vez surgen nuevas creencias y deseos, y que algunos de ellos ejercen una presión sobre los antiguos. A algunas de estas presiones las denominamos contradicciones y a otras tensiones. Satisfacemos ambas mediante diversas técnicas. Por ejemplo, podemos simplemente desechar una creencia o deseo antiguo. O bien podemos crear una nueva serie de creencias y deseos para encerrar al molesto intruso, reduciendo la presión que las antiguas creencias y deseos ejercen sobre él y que este ejerce sobre aquellas. $\mathrm{O}$ bien podemos deshilar, y por lo tanto borrar, toda una serie de creencias y deseos -podemos dejar de tener actitudes hacia las oraciones que utilizan una determinada palabra (por ejemplo, la palabra Dios o flogisto)”20.

Es evidente que Rorty no pretende definir aquí qué es una creencia como si indagara por la esencia de ella. Sólo aspira a describir su funcionamiento, su praxis. Tampoco nos dice en qué hay que creer. Sólo en tal sentido el tema de las creencias es, a la postre, su “filosofía primera”. No hay una diferencia esencial entre verdad y justificación de sus creencias. Davidson, uno de los autores que Rorty considera paradigmáticos del pragmatismo actuall $^{21}$, y que cita con mucha frecuencia, es quizás mucho más contundente respecto a la relación de igualdad entre creencia y verdad. Dice: "Si tengo dudas concretas y específicas respecto a la verdad de una de mis creencias, sólo puedo resolverlas preguntando si está adecuadamente justificada (...). No me puedo saltar la justificación para centrar la atención en la verdad: cuando la pregunta se refiere a qué debo creer en este momento, evaluar la verdad y evaluar la justificación constituyen una misma actividad”22. Así como Wittgenstein consideraba

\footnotetext{
18 Para establecer una relación entre las comunidades científicas y la religión, véase Thomas Kuhn, $L a$ estructura de las revoluciones científicas (México: Fondo de Cultura Económica, 1992).

19 Rorty, ¿Esperanza o conocimiento?..., p. 32.

20 Richard Rorty, Objetividad, relativismo y verdad, traducción de Jorge Vigil Rubio (Barcelona: Paidós, 1996), p. 131.

21 Véase: Rorty, ¿Esperanza o conocimiento? ..., p. 10.

22 Véase: Rorty, Verdad y progreso, p. 31.
} 
que el significado de una palabra se deriva de su uso, de manera análoga Davidson considera que la verdad de una creencia está en su justificación. El que la verdad de una creencia se dé en su justificación coloca a la persuasión y a la retórica como aspectos esenciales en el discurso filosófico.

\section{3. Ética de los sentimientos}

A partir de la crítica a la representación podemos entender que la problemática ética en Rorty pasa por una crítica a las teorías filosóficas $^{23}$. De esa crítica él va a derivar una posición alternativa, que se encuentra ejemplificada en la lectura de novelas morales. ¿En qué consiste esa crítica a las teorías filosóficas? En el ensayo "Filósofos y novelistas”, Rorty califica como esencialismo el intento por parte de la filosofía de sustituir una narrativa por una teoría. La teoría de la esencia acerca de Occidente, por ejemplo, llevó a Heidegger a reconstruir la historia de la región como la historia del Ser, y a considerar a los filósofos, poetas y pensadores como guardianes y protectores de esa historia. El olvido del Ser es, entonces, el olvido de esa esencia primordial. Pero hay momentos en la historia en que, mediante una debida fundamentación, que viene a ser interpretada como una reapropiación de la tradición, se puede o se intenta -según Heidegger-redimir esa historia. Eso es lo que Heidegger viene a hacer, al intentar plantear de nuevo la pregunta por el Ser.

Para Rorty, no se debe aceptar que Heidegger haya podido establecer la esencia de una cultura entendida como la historia del ser. Esta es sólo una teoría más que aspira a encontrar ese hilo conductor invisible de la historia de Occidente, esa esencia a partir de la cual podemos explicar el devenir de la historia como el movimiento pendular del olvido y la rememoración progresiva del Ser. Pero no son las teorías filosóficas - dice Rorty-, como las de Heidegger, e incluso las de Horheimer y Adorno, etcétera, las que pueden dejarnos entender mejor el devenir de la historia como algo abierto, como una novela, y no como una teoría, esto es, como un sistema cerrado en sí mismo, autorreferencial, insensible ante el dolor ajeno ${ }^{24}$. Mediante la novela (especialmente la novela moral cuyo ejemplo se encuentra en Dickens) se aprecia la positiva relatividad de los asuntos humanos, sin llegar a ninguna descripción correcta y exclusiva de ese devenir, dispuesto a la aventura, sin concluir ni siquiera con un modelo de novela. En cierto modo, la novela está más cerca de la ironía. Supone un mundo contingente, puesto que los personajes de la novela envejecen y mueren; no nos vemos tenta-

23 No me voy a referir aquí a la ética individual frente a la ética social que Rorty desarrolla en Contingencia, ironía y solidaridad, traducción de Alfredo Eduardo Sinnot (Barcelona: Paidós, 1996), segunda parte.

24 Véase: “Filósofos, novelistas y comparaciones interculturales: Heidegger, Kundera y Dickens”. Aunque en este ensayo Rorty deforma el planteamiento de Heidegger, y parece desconocer el sentido originario de lo que los griegos consideraban como teoría (contemplación), es conveniente señalar que, en efecto, la teoría moderna, desarrollada especialmente por la ciencia, y emulada por la filosofía, no nos sensibiliza, como él afirma, ante el dolor ajeno. Sin embargo, esto no es toda la verdad. En la práctica de la ascesis, a la cual estuvo ligada la filosofía durante algunos momentos de su historia, y considerada precisamente como el deshacer toda comprensión, toda teoría del mundo, se da la experiencia del otro como otro, se abre la sensibilidad ante lo otro. Rorty desconoce ingenuamente esto. La teoría de Rorty sobre la ascesis es sólo un prejuicio más que proviene de las teorías metafísicas racionalistas, que pretenden dar cuenta de algo, sin experimentarlo, esto es, como si fuera un "objeto", siendo insensibles ante la verdad misma de lo que está en cuestión, y generalizando a partir de datos particulares, contingentes, que por lo demás están incorrectamente interpretados. Veáse: Eliot Deutsch, comp., Cultura y modernidad: perspectivas filosóficas de Oriente y Occidente, traducción del inglés de David Sempau (Barcelona: Kairós, 2002). 
dos a adoptar una actitud ante ellos para luego extenderla a todo tipo de personas. En cambio, "los libros que tratan de ideas -dice Rorty- tienen el aspecto de descripciones de relaciones eternas entre objetos eternos”25.

La ironía es el saber acerca de la contingencia del propio vocabulario concluyente. Es decir: es un saber que acepta su propia imposibilidad de convertirse en algo definitivo, absoluto, que pueda ser considerado legítimamente como paradigma para todos los hombres y para todos los tiempos y culturas. La filosofía tradicional, la que considera que la moral descansa en la metafísica, ha intentado hacer valer sus derechos a la universalidad mediante la representación de la existencia de un Dios, o de un a priori (imperativo categórico) no discutible, ahistórico y eterno. En esos casos, la moral se da como el conocimiento de esa ley fundamental que nos prescribe (por deducción) la forma de nuestra conducta. La moral pasa por el conocimiento de esa esencia, pero no por los sentimientos, o, en otras palabras, por la representación de un objeto, esto es, el objeto de la moral y su fundamento. Esa es una herencia socrática y platónica: la de que el progreso en la moral es consecuencia del conocimiento de las ideas, así como el progreso en la ciencia es consecuencia del progreso de la representación de los objetos.

Sin embargo, en todos estos casos se puede estar extrapolando, como dogma, las creencias contingentes de una comunidad, llámese cristiana, moderna, europea, musulmana, etcétera, en suma, haciendo aparecer sus creencias contingentes como teorías universales, y, mediante la manipulación de los sentimientos (culpa, castigo, miedo, etcétera), difundiendo tales teorías como un deber ser para toda otra comunidad. Con ello quedan puestas las bases para el ejercicio de la crueldad a nombre de la moral. El que no es cristiano no es ser humano, y el que no es kantiano está en un error (no ha alcanzado la mayoría de edad), así como un judío para un fascista no es un ser humano. Desde concepciones ahistóricas de lo humano se ejerce la crueldad a nombre de una comunidad que se representa a sí misma como el paradigma de lo humano. De esta manera, en la moral no importan en ningún sentido los argumentos fundadores, porque la moral no pasa por el conocimiento sino por los sentimientos. De igual manera, no tiene ningún interés para un pragmatista rebatir o refutar los argumentos de quienes aún intentan fundamentar la moral en un concepto universal, porque de lo que se trata es de la utilidad. Decir que Dios quiere que demos la bienvenida al extraño que golpea nuestra puerta no es decir que Dios exista, o que no exista; es decir que "la hospitalidad es una de la virtudes de las que nuestra comunidad más se enorgullece"26. En otras palabras: no importa lo que alguien personalmente crea como fundamento de su moral; lo que importa es el resultado de su creencia como extensión de la solidaridad en una comunidad de la que él hace parte. Según Rorty, buscar qué es lo que tienen en común todos los hombres siempre se hará desde las condiciones contingentes de lo que tienen en común unos pocos. Más que tener una visión más clara de lo que tienen de común todos los hombres, se trataría de tejer una práctica de la solidaridad ${ }^{27}$ con la mayor cantidad posible de seres humanos. En otras palabras: no encontrar o indagar lo común a todos a partir del conocimiento de algo universal, que actúa como pegamento absoluto (y que no expresa sino la contin-

\footnotetext{
Rorty, Contingencia..., p. 127.

Rorty, ¿Esperanza o conocimiento? ..., pp. 9697.

27 Rorty, ¿Esperanza o conocimiento?..., p. 99.
} 
gencia como categoría generalizada), sino ir uniendo entre grupos particulares y diferentes mediante un millar de puntadas, invocando mil cosas menudas en común entre sus miembros, en lugar de invocar una única cosa grande $^{28}$. "Eso no quiere decir -agrega Rorty- que los intentos de pensar en términos de abstracciones tales como hijo de Dios o de humanidad o ser racional no hayan hecho bien" ${ }^{29}$. Pero estas se basan en el proceso de reconocer una solidaridad ya dada, mediante abstracciones de condiciones históricas contingentes, y no en la práctica de crearla. "Debiéramos tener en la mira a los marginados -dice Rorty-: personas que instintivamente percibimos aún como ellos y no como nosotros" ${ }^{\text {30 }}$. Rorty afirma que hay un progreso moral en la medida en que podemos ya no servirnos para la moral de esas categorías abstractas, donde la moral se pretende deducir a partir de principios, y acceder a la experiencia de solidaridad referida al dolor y a la humillación del otro. Para ello, son más útiles las novelas o las descripciones de ese dolor y esa humillación.

Para Rorty, la moral es propia del sentimiento, no de la razón. La razón está motivada por la abstracción y lo universal. El sentimiento se dirige siempre a lo particular, a lo concreto, y, al mismo tiempo, a una situación social. Se requieren descripciones, narraciones, donde la sensibilidad puede ser afectada, involucrada. Son más útiles las novelas morales como la de Dickens que los tratados filosóficos. Son más útiles las descripciones explicativas que realizaron muchos hombres en el pasado que los sistemas morales racionales. Dice Rorty: “La redescripción fue practicada por los cristia- nos primitivos cuando explicaron que la diferencia entre judíos y griegos no era tan importante como se había pensado. Es practicada por las feministas contemporáneas, cuyas redescripciones del comportamientos sexual y de los acuerdos matrimoniales suenan tan extrañas a muchos hombres como sonó a los escribas y fariseos la indiferencia de San Pablo a las distinciones tradicionales judaicas"31. Siguiendo a Rorty, podríamos afirmar en el mismo sentido: son más útiles las descripciones de Bartolomé de las Casas respecto al trato que sufrieron los indígenas en la conquista española que los tratados de Hegel. En suma, lo que nos une en la solidaridad no es la razón, sino la creciente práctica extensiva de ser sensibles ante el dolor ajeno dentro de condiciones contingentes, esto es, limitadas a una comunidad específica, y cuyo porvenir es desconocido pero esperanzador. Sólo así se supera una moral de la obligación de la éticas racionalistas y dogmáticas, desde cuyas abstracciones, según Rorty, se ejerce la crueldad.

\section{Problemática general}

En síntesis, la crítica a la representación en Rorty desemboca de igual manera en una ética, en la que no es el conocimiento ni ninguna ciencia la que puede otorgar el sentido de una práctica moral como solidaridad. Hasta aquí queda claro sólo lo que Rorty puede decirnos desde sus prejuicios. ¿Qué podemos nosotros agregar desde los nuestros? Quisiera en esta última parte de este ensayo extender algunas de sus premisas o presupuestos más allá de lo que quizás él podría admitir como su posición, con el fin

\footnotetext{
28 Rorty, ¿Esperanza o conocimiento? ..., p. 100.

29 Rorty, Contingencia..., p. 214.

30 Rorty, Contingencia..., p. 214.

31 Rorty, Contingencia..., p. 101.
} 
de dilucidar algunas otras consecuencias de interés respecto a su crítica al conocimiento como representación, y en especial para un diálogo (?) entre el pragmatismo y una ética más amplia o, al menos, diferente (¿análoga?). Los temas más cruciales que voy a problematizar, sin intentar llegar a conclusiones definitivas son: una ética de los sentimientos sin referentes; un referente no unívoco; una naturaleza humana sin esencia; $\mathrm{y}$, por último, las creencias sin fundamento.

\subsection{Una ética de los sentimientos sin referentes}

Considero un gran adelanto el que se formule la ética dentro del ámbito de los sentimientos. En efecto, actuar inspirado por deducciones lógicas desde una fría razón cuyo $a$ priori universal me permite, como si fuera un simple mecanismo, deducir en cada momento lo que debo hacer, es algo utópico, teórico, y corresponde a una idea del hombre como un ser dividido entre facultades, lo cual corresponde, a su vez, a una idea de ciencia y de conocimiento que proviene del paradigma de la física de Newton. Tampoco considero pertinente partir de una moral que proviene de una metafísica dogmática, en la que Dios se convierte en un reemplazo de un motor inmóvil y se reduce a ser un objeto de conocimiento, y que, como primer principio, legisla de manera clara e inequívoca acerca de todas las cosas, de tal manera que podemos deducir y dictaminar a partir de nuestro pretendido conocimiento acerca de él respecto a todos los asuntos morales y humanos. En todo ello está precisamente implicado el que se conciba al hombre fundamentalmente como un animal racional, esto es, como un animal que “conoce”, y, por consiguiente, se pretende que él posee un conocimiento absoluto, unívoco, de lo absoluto, hasta el punto de que no existe ningún misterio, y el mismo fundamento universal (cognitivo o racional) que está dado desde alguna metafísica es la constatación de la ausencia de todo misterio.

Quizás deberíamos preguntarnos, como Rorty lo sugiere: ¿por qué estamos tan tentados a definirnos a partir del conocimiento?. Quizás debamos replantear el tema del hombre y de la ética desde aquellas tradiciones en las que se lo concibe como un ser que se construye desde la voluntad, desde sus creencias, desde su relación con el otro ${ }^{32}$. Pero tampoco considero suficiente afirmar, como lo hace Rorty, que no exista ningún referente desde el cual podamos acceder, no a un conocimiento de lo universal en el hombre, pero sí a una experiencia personal de lo universal en el hombre, suficientemente inspiradora en mi relación con el otro. No todo lo que nos "representamos" se ha de convertir necesariamente en objeto de conocimiento, ni tampoco en un frío ideal regulador que proviene de la razón pura. Necesitamos “entender"33 algo acerca de aquello que puede inspirar los sentimientos en los

32 Véanse por ejemplo los trabajos de Humberto Maturana y Francisco Varela. Desde la biología, ellos consideran que lo que define a los primates es la manera como experimentan "al otro" y como construyen relaciones a partir de ello.

33 El término "entendimiento" que aquí voy a mencionar frecuentemente puede ser equivalente al término "prospección” que utiliza Mauricio Blondel cuando afirma: "Hay, pues, un primer tipo de conocimiento que, siendo perfecto en su género, es directo; está al servicio de nuestras intenciones reales y actuales, ligado a nuestra vida entera, vuelto hacia el futuro (...). Este conocimiento es capaz de crecer en claridad y en precisión sin perder nada de su carácter sintético y práctico (...)”. El punto de partida de la investigación filosófica, traducción de Jorge Hourton (Barcelona: Herder, 1967), p. 22. Quizás no sobre dar un ejemplo práctico para entender el término "entender": nadie quiere ser conocido, lo que queremos es ser comprendidos, que nos entiendan. Es diferente conocer a entender. Hay siempre algo de generosidad cuando entiendo a otro, más no necesariamente cuando le conozco. 
que encuentro con el otro "lo que nos es común”. En este sentido, por la fuerza de los sentimientos o de cualquier sentimiento, el sentido de lo moral no es necesariamente despertado. El sentimiento del dolor ajeno puede llevar igualmente a la violencia, a la venganza o al resentimiento. El sentimiento es la base de la moral, pero no es suficiente.

Siempre hay referentes, y son necesarios, pero no han de ser considerados como objetos de conocimiento. Tener un referente, por ejemplo, es tener claro por dónde hay que seguir en el camino para llegar a un sitio, es tener un entendimiento acerca de lo que es el camino. Pero no significa tener un conocimiento del sitio ni del camino como objeto ya conocido o como esencia inmutable. El entendimiento acerca del referente puede cambiar, el camino puede cambiar, y nosotros mismos con él. Pero el referente no debe desaparecer: su necesidad es la necesidad de la esperanza. Una esperanza sin referentes es lo mismo que nada. El referente respecto al fundamento no es propiamente objeto de conocimiento, sino "momentos metafóricos del significado" en un sentido más sacramental. No son ideales reguladores de la acción, sino que son inspiradores, capaces de despertar los sentimientos apropiados para la acción moral, como es el sentimiento de la esperanza a través de la solidaridad. La esperanza no es unívoca: ella nos indica que el camino que caminamos tiene un sentido, pero eso no quiere decir que no pueda ser reconducido según las exigencias y necesidades de quien lo recorre, de aquellos con los que lo recorre, y según lo que se nos va mostrando a medida que lo recorremos.

\subsection{Un “referente” no unívoco}

El ideal de conmensurabilidad, entendido como el ideal de conocimiento total de lo absoluto o del fundamento (entendido como Dios o estructura a priori de la subjetividad), es precisamente la base de todo fundamentalismo, incluso del fundamentalismo científico, que en la filosofía analítica se expresa como el ideal de un lenguaje perfecto. No se trataría de establecer un conocimiento unívoco de lo absoluto, entendido como el esfuerzo de dar cuenta de lo trascendente o de lo trascendental, o, en el polo opuesto, como la absolutización de lo contingente en el ateísmo dogmático ${ }^{34}$, o mediante el ideal científico de un lenguaje perfecto. Se trataría, por el contrario, de reconocer la necesidad de lo contingente en nuestra interpretación de los referentes acerca de lo absoluto, pero, al mismo tiempo, de no cancelar la dilucidación de ese referente, abortando el proyecto de una metafísica. Necesitamos un referente desde el cual podamos acceder a un diálogo, un "nuevo lenguaje sobre lo trascendente” (como diría Scannone) desde el cual podamos acceder a un sentimiento del "nosotros" en donde descubramos "lo que nos es común”, sin perder las diferencias, y enriqueciendo, al compartir nuestros mundos, las posibles elecciones. Sólo así sería posible superar el dogmatismo que está siempre al acecho cuando, desde posiciones cognitivas o radicalmente anticognitivas, en suma, equívocas respecto a lo que más nos concierne en un sentido existencial (la búsqueda del sentido, de un referente, de la unidad), se busca determinar conceptualmente una esencia universal o despacharla sin más.

34 También los ateos tienen su liturgia secular, sus devociones inconscientes o concientes. Desde una perspectiva pragmática, no debemos preguntar, por ejemplo, si los ateos o los cristianos tienen razón, sino qué ventajas podríamos extraer del diálogo con ellos, qué aspectos en común podríamos compartir en una tarea específica, por ejemplo, en la defensa de los “derechos humanos". 


\subsection{Una "naturaleza humana" sin sustancia}

Según Rorty, sólo es posible la libertad y la esperanza si se abandona esa pretendida objetivación que se cierne sobre el hombre a partir de representaciones unívocas de su naturaleza universal, frente a la cual tenemos que adecuarnos, convirtiéndonos en un en sí. Sin embargo, al no definir una esencia de lo humano desde una ontología, se está preparando el camino para que lo contingente sea lo que dictamine la esencia de lo humano. Así, el hombre se define (subrepticiamente) como un conjunto de necesidades, o como una forma cuyo contenido es llenado por la contingencia, o, lo que es lo mismo, por una libertad sin referentes. Una libertad sin referentes fundamenta muy bien el liberalismo de una sociedad donde todo vale.

Rorty establece constantemente un juego semántico que podemos denominar la lógica del sí, pero no. Por ejemplo: no hay naturaleza humana, pero podemos definirla y representarla así: "Para los fines de la deliberación y la conversación moral y política, una persona es simplemente esa red, igual que para los fines de la balística es un punto de masa, o para los fines de la química un agregado de moléculas. Es una red que constantemente se vuelve a tejer a sí misma (...), es decir, no por referencia a criterios generales (por ejemplo: reglas de significado o prejuicios morales), sino de la forma aleatoria en que las células se reajustan a sí mismas para hacer frente a las presiones del entorno" ${ }^{35}$. Es claro que esta imagen de la naturaleza humana, sin esencia, tiene una "esencia" muy maleable para el capitalismo: es el hombre instrumento. Sólo forma sin contenido. Gracias a ello puede y debe readaptarse a condiciones de producción específicas; en suma, es un programa de adaptación al medio, donde cualquier criterio de validez puede funcionar, con tal de que alcance los fines preestablecidos en una comunidad. Esta imagen sigue siendo una imagen acerca del hombre, cuya esencia consiste en lo contingente, pero no dirigido a lo incondicionado, sino encerrado en sus límites, muy bien disciplinado para los fines productivos. Con ello se pretende garantizar que cada uno se haga a sí mismo, se cree a sí mismo. Sin embargo, esa garantía es sólo teórica. En la práctica, sin haber referentes, cada uno se da su propia naturaleza configurada desde sus prejuicios y desde sus opiniones, desde la imposibilidad de una relación con lo otro. Desde la contingencia en la que se encuentra sometido o alienado puede aferrarse a ella como una especie de segunda naturaleza. Superar las determinaciones contingentes de la naturaleza supone, pragmáticamente, partir de una libertad con esencia, y esto implica la necesidad de un referente que no provenga de una teoría, sino de la esperanza. Que no esté definido, sino proyectado, y que sepa inspirar los sentimientos de compasión. Referente que pueda ser dilucidado, aunque no conocido. De lo contrario, no es posible que desde ese marco de una libertad como gratuidad pueda haber una superación de la pretendida representación. Representarme la naturaleza humana y la existencia desde lo contingente en lugar de hacerlo desde lo absoluto es una forma de remplazar un ídolo por otro. Esa libertad sin esencia es colonizada muy pronto por cualquier tipo de condicionamiento, desde el cual lo contingente no rebasa los límites de lo contingente. Justifica el contexto al cual pertenece al proyectarlo como la realidad y sin poder superarlo. En consecuencia, el hombre según Rorty es un ser con necesidades. Es una

35 Rorty, Objetividad..., p. 270. 
definición que se adecúa al hombre sumido en la sociedad de consumo. Al no ser la definición de su esencia, sin embargo, pragmáticamente, lo condena a esa esencia. Pero el hombre no se define por sus necesidades: se encuentra limitado por estas, que es diferente. Esta limitación puede "limitar" la expresión de lo que es realmente como persona, pero no puede cancelar su esencia como un asunto contingente.

Por otro lado, hoy en día la interpretación según la cual el cristianismo se funda en la idea de hombre como sustancia no es fácil de admitir en todos los autores considerados “cristianos”. Para muchos esta interpretación no es sino una influencia griega en la tradición cristiana. Algunos pensadores cristianos, especialmente los existencialistas o influenciados por el existencialismo de Gabriel Marcel, como Ferdinand Ebner, contraponen la idea de persona a la idea de sustancia o de una naturaleza humana fija y estable, ajena al devenir ${ }^{36}$. La categoría de persona es existencial; en ella, el ser se hace, deviene. No es algo objetivo y ahistórico. Y se hace en la relación con Dios que se revela sólo en la historia. "La verdadera y plena realidad del hombre sólo se constituye en su apertura dialógica al tú. Si estas realidades son entendidas, no como meras relaciones que sobrevienen una vez constituidos en su ser los términos que las constituyen, sino como entidades nuevas irreductibles, es fácil resolver las antinomias que plantean los conceptos existenciales trascendencia y mundo", sujeto y objeto, etcétera ${ }^{37}$.

En esta perspectiva, lo humano se define en su devenir existencial como persona ante otro, desde una práctica concreta, desde una acción movida por "sentimientos inspirados desde un referente”, desde el cual la contingencia es sólo un punto de partida para algo más grande. Aquello, más grande, no es una cómoda solución ni una reducción a partir de la representación de una esencia universal. Rorty tiene razón cuando afirma que no hay una representación universal de la verdad, de la esencia de lo humano en tanto que sustancia, pero olvida que sí hay una experiencia donde la verdad se revela: la fe. En ella la verdad no se revela como una representación acerca de cosas u objetos, y menos aún, como ciencia. La verdad como vida $\mathrm{y}$ amor no es objeto alguno, no es un ente. Es también un desafío, un referente metafórico desde el cual se inspira el sentido de la esperanza. Como afirma Daniel Herrera, "el Dios de la fe no es el tapahuecos de la ignorancia humana (...) no es la garantía de un orden social. Tampoco es un título de seguridad que nos dispense de participar en los riesgos que acompañan el existir humano. El Dios de la fe es aquel que en cada momento problematiza nuestra seguridad y nuestra tendencia a la facilidad de la buena conciencia. La existencia no es un destino regido por Dios sino un proyecto que debemos asumir plenamente: el proyecto de hacer de nuestra persona una personalidad que se acerca a la plenitud de Cristo" 38 .

\subsection{Creencias sin fundamento}

Todos terminamos siendo creados por los límites de nuestras creencias y justificándonos a nosotros mismos a partir de ellas. Rorty no justifica desde un conocimiento acerca de esencias su creencia en el hombre como "en esencia” un conjunto de necesidades, pero

36 Véase también el estudio de Daniel Herrera, La persona y el mundo de su experiencia: contribuciones para una ética fenomenológica (Bogotá: Universidad de San Buenaventura, s. f.).

37 Alfonso Lopez Quintas, Pensadores cristianos contemporáneos: Wust, Haecker, Ebner, Zubiri, Przywara (Madrid: BAC, 1968), p. 155.

38 Herrera, La persona..., p. 80. 
ese prejuicio opera en su heurística de una manera evidente, ya que justifica su creencia en un mundo secular y en una moral secular. Cree en ello y lo justifica acudiendo a aquello que fortalece su "fe" (falacia por petición de principio). Su filosofía se define por un "acto de fe”. Por nuestra parte, podemos preguntar, incluso si pensamos lo útil en la perspectiva más amplia, más “útil”: ¿de cuál de todas nuestras creencias podemos sacar las mejores consecuencias prácticas para el hombre, no meramente en tanto que un ser con necesidades (necesidades que requieren ser colmadas, por supuesto), o como un ser que conoce, sino como un ser relacional, total, en permanente experiencia de unidad con el otro, con lo Otro, en permanente transformación?

Es aquí donde Davidson es muy esclarecedor. Dice: "Los pragmatistas piensan que, si algo no supone diferencia en la práctica, tampoco debe marcar ninguna diferencia en la filosofía. Esta convicción hace que se muestren suspicaces ante la distinción entre justificación y verdad, pues se trata de una diferencia que no supone diferencia alguna a la hora de decidir qué hacer"39. En otras palabras, si es completamente indiferente en la práctica el creer en la esencia o no creer en ella, entonces la verdad sigue siendo la justi- ficación de nuestras creencias, sean las que fueren, e incluso, la creencia en la esencia. Siguiendo las consecuencias de este planteamiento: con todo ello, por razones pragmáticas vamos a negar el pragmatismo y a replantear la necesidad de encontrar un fundamento más sólido incluso para éste. Tendríamos que dilucidar si es mucho más “útil” trascender la utilidad como satisfacción de necesidades, y pensar la solidaridad no meramente como un sentimiento reactivo ante el dolor, sino como algo que es inspirado por el sentimiento de la esperanza, esperanza que a su vez descansa en un referente inalienable. Así, la solidaridad está lejos de una fría y calculada estrategia de administración pública (empeñada en acabar con el hambre), y atañe, a la vez, a la necesidad humana de compartir y de recibir, de encontrar referentes inspi-radores. El dar o compartir no responde a una fría obligación moral sino que hace parte de la identificación con el nosotros, un nosotros que no proviene de un conocimiento de una sustancia universal, ni de un mero sentimiento reactivo ante el dolor, sino de un referente analógico, esto es, de la necesaria experiencia de unidad ${ }^{40}$ con lo Otro, con el otro, inspirada por el sentimiento de esperanza, y por la necesidad pragmática de encontrar un sentido a lo que se hace, se sueña y se desea. Entonces, es posible abrirse a

39 Rorty, Verdad y progreso, p. 31.

40 Sobre la unidad hay que desarrollar más la idea opuesta de separación, o mejor, de interrupción de esa unidad, como el "espacio" en el que ocurren todas nuestras experiencias de lo otro en la sociedad capitalista. Todas nuestras relaciones se tienden a objetivar, incluso las más cotidianas, ya sea desde una teoría o desde un uso. A este respecto, dice Mauricio Blanchot: "también puedo desear, por el arrebato de la comunicación, unirme inmediatamente a ti en el instante, atraer a lo otro en mí con una efusión en la que no subsisten ni el uno ni el otro: bien sea una ilusión de verdad o una verdad de ilusión, el deseo tiende a esta relación unitaria inmediata, igual que todas las demás relaciones tienden a establecer entre los seres y entre las cosas, pero sólo de modo mediato, una forma de unidad o una forma de identidad”. Maurice Blanchot, Diálogo inconcluso (Caracas: Monte Ávila Editores, 1970), p. 123. Esta es la clave para comprender que en la acción, de manera a priori, ya existe ese ideal, y existe como deseo puro de unidad con todo lo que existe, y desde la cual toda relación no es propiamente una separación, sino como una interrupción de la unidad. Interrupción que escapa a toda medida. Y agrega Blanchot: "Y así sería la relación del hombre con el hombre, cuando ya no hay entre ellos la proposición de un Dios, ni la mediación de un mundo, ni la consistencia de una naturaleza.” Diálogo..., p. 124. 
una referencia mucho más abarcadora, esto es, más poderosa, que inspira nuestra acción práctica hacia una creencia que, al no estar limitada y encerrada en los límites de lo contingente, puede experimentar lo real de otra manera, y, al mismo tiempo, puede reconocer con modestia que no tiene un conocimiento absoluto de la verdad.

\section{Conclusiones}

Si es posible una nueva síntesis que provenga de una mirada no unívoca ni equívoca, desde la cual podamos pensar todos estos asuntos de una manera menos reactiva y más clara $^{41}$, entonces no sólo el pragmatismo, sino muchos de los temas fundamentales que aborda Rorty de manera no frontal sino evasiva (la ontología y la metafísica), se podrían reconsiderar. Eso supondría, sin embargo, hacer una suerte de inventario acerca de aquello que en el pensamiento de Rorty nos permite realmente extraer las mejores consecuencias en términos pragmáticos, aunque para ello tengamos que “superar” el pragmatismo. Un pensamiento que logre dilucidar la esencia de lo humano desde un referente analógico (y no desde un conocimiento universal), quizás no tenga como consecuencias ideológicas el ejercicio de la intolerancia y la crueldad que Rorty acertadamente denuncia, imponiendo "esencias universales” unívocamente definidas a nombre de la verdad representada en un conocimiento científico o metafísico.

Pero ello implica, de igual manera, repensar las “necesidades” quizás desde un marco teórico diferente a aquel en el que en el pragmatismo pueden ser pensadas. Algo análogo ocurre con el tema de los sentimientos y la naturaleza humana, y con el mismo tema del valor del conocimiento. Quizás deberíamos comenzar por desmontar el prejuicio de Rorty acerca de que toda búsqueda sobre la esencia deviene necesariamente en ejercicio de la crueldad o de la insensibilidad. Se trataría de señalar que ello ha sido posible desde concepciones unívocas o equívocas, desde las cuales han sido inevitables tales consecuencias. En el contexto de una "hermenéutica analógica” puede ser replanteada tal búsqueda y ver en ella la expresión cabal de la necesidad espiritual de fundamentarse en referentes que logren inspirar una práctica solidaria, una ética, y, por ende, dar sentido de lo que se hace y se proyecta. Este saber requiere ser dilucidado adecuadamente, sin caer en posiciones representacionistas o antirrepresentacionistas, tan excluyentes como insuficientes. Es desde el símbolo, la analogía, la metáfora, desde donde algunas de estas cuestiones pueden ser pensadas de una manera más amplia, pues el símbolo, como lenguaje contingente de una comunidad acerca de lo esencial, reúne tanto aspectos cognitivos como no cognitivos capaces de inspirar una ética de los sentimientos y una metafísica no dogmática.

Por otro lado, es necesario recordar que la metafísica o la ontología está además “motivada” por un interés “pragmático”, no en un sentido utilitario, sino en el sentido de "servir" con ello al hombre, o en el sentido de sentar las bases o las condiciones de posibilidad desde las cuales es posible la esperanza. La esperanza como sentimiento futuro y presente, que no niega el pasado, ha de inspirar (no regular) nuestras acciones éticas. Esta esperanza, en tanto que no es meramente reactiva ante el dolor (asunto este que no ha de ser desdeñado, pues las muchas necesidades requieren ser atendidas), tiene conse-

41 Como lo plantea Mauricio Beuchot. Véase: Tratado de hermenéutica analógica (México: Universidad Nacional Autónoma de México, 1997). 
cuencias mucho más provechosas: ilumina el sentido de lo que se hace. Así, desde la dilucidación de la esencia (en una perspectiva analógica) y desde la pregunta por el sentido de la utilidad, podríamos superar todo utilitarismo. Ello nos lleva directamente al tema que Rorty desdeñaría enfáticamente: pensar la esencia de lo útil. Por ahora, y como una conclusión que no puede terminar sino con la formulación de varios interrogantes, recordemos la afirmación de Heidegger: "Falta mucho para que nosotros pensemos sobre la esencia del obrar en forma suficientemente decidida. Se conoce el obrar sólo como el efectuar un efecto. Su actualidad es apreciada por su provecho. Pero la esencia del obrar es el consumar. Consumar quiere decir: realizar algo en la suma, en la plenitud de su esencia”42.

\section{Bibliografía}

Beuchot, Mauricio. Tratado de hermenéutica analógica. México: Universidad Nacional Autónoma de México, 1997.

Blanchot, Maurice. Diálogo inconcluso. Caracas: Monte Ávila Editores, 1970.

Blondel, Mauricio. La acción. Introducción, versión y notas, Juan María Isasi. Madrid: BAC, 1996.

_El punto de partida de la investigación filosófica. Trad., Jorge Hourton. Barcelona: Herder, 1967.

Dickens, Charles. Oliver Twist. Trad., Enrique Leopoldo Verneuil. Barcelona: Planeta, 1994.

Eco, Humberto. Apocalípticos e integrados. Trad., Andrés Boglar. Serie Palabra en el Tiempo. Barcelona: Lumen, 1993.
Foucault, Michel. Hermenéutica del sujeto. Trad., Fernando Álvarez Uría. Madrid: Piqueta, 1994.

_-_-Orden del discurso. Trad., Alberto Gonzáles Troyano. Barcelona: Tusquets, 1987.

_L L verdad y las formas jurídicas. Trad., Enrique Lynch. México: Gedisa, 1983.

Gómez Pardo, Rafael. “La educación como práctica filosófica”. Itinerario Educativo (Universidad de San Buenaventura, Bogotá) 32 (1988), p. 179.

Heidegger, Martín. Arte y poesía. México: F.C.E., 1978.

_L L proposición del fundamento. Traducción y nota, Félix Duque y Jorge Pérez de Tudela. Barcelona: Serbal, 1991.

Serenidad. Versión castellana, Yues Zimmermann. Odos, 1989.

— Ser y tiempo. Trad., José Gaos. México: F.C.E., 1995.

Herrera, Daniel. La persona y el mundo de su experiencia: contribuciones para una ética fenomenológica. Bogotá: Universidad de San Buenaventura, s. f.

Kurosawa, Akira. Autobiografía o algo parecido. Madrid: Fundamentos, 1990.

Levinas, Emmanuel. Totalidad e infinito: ensayo sobre la exterioridad. Salamanca: Sígueme, 1971.

Marcuse, Herbert. "La nueva sensibilidad”. Un ensayo sobre la liberación. México: Joaquín Mortiz, 1969.

Maturana, Humberto. La realidad: ¿Objetiva o construida? Barcelona: Anthropos, 1995.

42 Martín Heidegger, Carta sobre el humanismo, trad. de Victoria Prati de Fernández, $3^{\mathrm{a}}$ ed. (Buenos Aires: Sur, 1960), p. 65. 
_El sentido de lo humano. Bogotá: Tercer Mundo, 1998.

Max, Born. "La física de mi generación”. Universitas (revista alemana de ciencias y letras) II.3 (1964), pp. 225235.

Merleau-Ponty, Maurice. El lenguaje indirecto y las voces del silencio. Argentina: Galatea, 1957.

Morín, Edgar. Amor, poesía, sabiduría. Bogotá: Cooperativa Editorial Magisterio, 1998.

Mukarovsky, Jan. Escritos de estética y semiótica del arte. Edición crítica, Jordi Llovet. Barcelona: Gustavo Gili, 1977.

Ricoeur, Paul. Hermenéutica y acción. Trad., Mauricio M. Prelooker. Buenos Aires: Docencia, 1985.

Rorty, Richard. Contingencia, ironía y solidaridad. Trad., Alfredo Eduardo Sinnot. Barcelona: Paidós, 1996.

Cultura y modernidad: Perspectivas filosóficas de Oriente y Occidente. Traducción del inglés, David Sempau. Barcelona: Kairós, 2001.

_Ensayos sobre Heidegger y otros pensadores contemporáneos. Trad., Jorge Vigil Rubio. Barcelona: Paidós, 1993.

¿Esperanza o conocimiento? Una introducción al pragmatismo. Trad., Eduardo Rabosi. Buenos Aires: F.C.E., 1994.

L La filosofía en la historia: Ensayos de historiografía de la filosofía. Barcelona: Paidós.
__ La filosofía y el espejo de la naturaleza. Trad., Jesús Fernández Zulaica. Madrid: Cátedra, 1979.

----El giro lingüístico: Dificultades metafilosóficas de la filosofía lingüística. Trad., Bagriel Bello. Barcelona: Paidós, 1998.

-Objetividad, relativismo y verdad. Trad. Jorge Vigil Rubio. Barcelona: Paidós, 1996.

__ Verdad y progreso. Trad., Ángel Manuel Faerna García Bermejo. Barcelona: Paidós, 2000.

Russell, Bertrand. La perspectiva científi-ca. Barcelona: Ariel, 1989, pp. 79-91. (metafísica, ciencia y religión), y 117-162 (técnica y sociedad).

Varela, Francisco. Ética y acción. Traducción del inglés, Cristóbal Santa Cruz. Santiago de Chile: Andros, 1996.

Vattimo, Gianni. Creer que se cree. Trad., Carmen Revilla. Barcelona: Paidós, 1996.

Fin de la modernidad: Nihilismo y hermenéutica en la cultura posmoderna. Trad., Alberto Bixio. Barcelona: Planeta-Agostini, 1994.

Vattimo, Gianni y Jacques Derrida. La religión. Argentina: La Flor, 1997.

Wittgenstein, Ludwig. Los cuadernos azul y marrón. Madrid: Tecnos, 1993.

_-Tratactus logico-philosophicus. Trad., Jacobo Muñoz e Isidoro Requera. Madrid: Alianza, 1987.

Zubiri, Xavier. El hombre y la verdad. Madrid: Alianza, 1999. 